\title{
ABSCESO RENAL EN PEDIATRÍA: REPORTE DE 2 CASOS
}

KAREN CAÑAS ${ }^{1}$, GLORIA GALÁN GUTIÉRREZ², DIOCEL ORLANDO LANCHEROS², JUAN JOSÉ LÓPEZ PÉREZ²

\author{
${ }^{1}$ Médico hospitalario. Unidad de Servicios de Salud Tunal. \\ ${ }^{2}$ Pediatra. Servicio de Pediatría. Unidad de Servicios de Salud Tunal. \\ Correspondencia: Dr. Juan José López Pérez, Hospital El Tunal, Bogotá, Colombia. \\ Teléfono (571)2324807, correo electrónico juanj.lopezp26@yahoo.es
}

Recibido: 8 de mayo de 2017 Aceptado: 19 de septiembre de 2017

\section{Resumen}

Introducción. Los abscesos renales tras una infección urinaria en pediatría no son frecuentes.

Reporte de los casos. Se trata de dos niñas con infección urinaria, de 13 y 8 meses, que desarrollan abscesos renales. En ambas, después de un uroanálisis sugestivo de infección urinaria, se inicia manejo empírico con amikacina. El reporte del urocultivo muestra crecimiento de Escherichia coli (E. coli) $>100000 \mathrm{UFC} / \mathrm{ml}$, sensible a dicho antibiótico, con ecografía renal inicial normal en el primer caso y en el segundo con nefromegalia derecha. A pesar del manejo antibiótico persistió la fiebre por más de tres días, por lo que se sospecha una complicación supurada. En el primer caso, la ecografía renal de control refleja imágenes sugestivas de absceso renal, pero en el segundo, a pesar de ecografías seriadas, solo se reportó la nefromegalia, que llevó realizar una tomografía abdominal con contraste para confirmar el diagnóstico. El antibiótico inicial, a pesar de la sensibilidad in vitro, no fue capaz de controlar la formación de abscesos renales. En el primer caso, el proceso infeccioso se controló utilizando amikacina y ceftriaxona, pero en el segundo fue necesario meropenem y amikacina. En ningún momento se alteró la función renal. Es de anotar lo infrecuente que es el absceso renal en niños en nuestra institución, ya que no se ha encontrado ningún caso en varios años.

Conclusiones. El absceso renal en pediatría no es frecuente, se desarrolla principalmente tras una infección urinaria. Son necesarios una alta sospecha y un adecuado diagnóstico para orientar su manejo, ya sea solo médico o asociado a drenaje quirúrgico.

Palabras clave: infección urinaria; absceso renal; pediatría.

\section{KIDNEY ABSCESS IN PEDIATRICS: 2 CASE REPORTS}

\section{Summary}

Introduction: Renal abscesses are not common in pediatrics after urinary tract infections.

Case reports: The two cases involve two 8 and a 13 month old girls with urinary tract infections, who also develop renal abscesses. In both cases, after a urinalysis shows signs of urinary tract infections, empirical management with amikacin is initiated. The uroculture report shows a growth of Escherichia coli (E. coli) $>100,000 \mathrm{CFU} / \mathrm{ml}$, sensitive to the given antibiotic, with a normal initial renal ultrasound in the first case and right nephromegaly in the second 
case. Despite the antibiotic treatment, the fever persisted for more than three days, which is why a suppurative complication is suspected. In the first case, the renal ultrasound from the control suggests the presence of a renal abscess, but in the second case, despite serial ultrasounds, only nephromegaly was reported; therefore, an abdominal tomography with contrast was performed in order to confirm the diagnosis. The initial antibiotic, despite in vitro sensitivity, was not able to control the formation of renal abscesses. In the first case, the infectious process was controlled using amikacin and ceftriaxone, but in the second case, meropenem and amikacin were necessary. At no point in time did the renal function change. It is important to note how infrequent renal abscesses in children are in our institution, given that there have not been any reported cases for several years.

Conclusions: Renal abscesses in pediatrics are not frequent; they develop mainly after a urinary tract infection. A high level of suspicion along with an adequate diagnosis is needed in order to guide its management, be it only medical or associated with surgical drainage.

Keywords: urinary infection; renal abscess; pediatrics.

\section{ABSCESSO RENAL EM PEDIATRIA: RELATO DE DOIS CASOS}

\section{Resumo}

Introdução. Os abscessos renais após uma infeção urinária em pediatria não são frequentes.

Relatório dos casos. Trata-se de duas meninas com infeção urinária, de 13 e 8 meses, que desenvolvem abscessos renais. Em ambas, após uma análise de urina sugestiva de infeção urinária, se inicia manejo empírico com amikacina. O relatório da cultura de urina mostra crescimento de Escherichia coli (E. coli) $>100000 \mathrm{UFC} / \mathrm{ml}$, sensivel a este antibiótico, com ultrassonografia renal inicial normal no primeiro caso e no segundo com nefromegalia direita. Apesar do manejo antibiótico persistiu a febre por mais de três dias, motivo de suspeita de uma complicação supurada. No primeiro caso, a ecografia renal de controle reflete imagens sugestivas de abscesso renal, mas no segundo, apesar de ultrassonografias seriadas, só foi reportada a nefromegalia, que levou a realizar uma tomografia abdominal com contraste para confirmar o diagnóstico. O antibiótico inicial, apesar da sensibilidade in vitro, não foi capaz de controlar a formação de abscessos renais. No primeiro caso, o processo infecioso foi controlado utilizando amikacina e ceftriaxona, mas no segundo foi necessário meropenem e amikacina. Em nenhum momento foi alterada a função renal. Vale anotar que o abscesso renal em crianças em nossa instituição é pouco frequente, já que não há registro de caso algum em vários anos.

Conclusões. O abscesso renal em pediatria não é frequente, se desenvolve principalmente após uma infeção urinaria. É necessário uma alta suspeita e um adequado diagnóstico para orientar seu tratamento, seja somente médico ou associado à drenagem cirúrgica.

Palavras-chave: infecção urinária, abscesso renal, pediatria

\section{Introducción}

La infección urinaria es una entidad frecuente en pediatría que responde rápidamente al manejo antibiótico adecuadamente seleccionado, dependiendo de las resistencias locales (1) y generalmente lleva un curso sin com- plicaciones, pero con potenciales riesgos a largo plazo y secuelas (2). Las complicaciones supuradas, como la formación de abscesos renales, no son frecuentes en niños (2). En el tiempo en el que hemos trabajado en la institución en la institución no se habían presentado casos de complicaciones supuradas, por lo que nos llamó 
la atención que, a pesar de un correcto manejo antibiótico, la evolución llevó a la formación de abscesos renales bilaterales.

\section{Descripción de los casos}

\section{Paciente 1}

Paciente femenina de 13 meses de edad, sin antecedentes relevantes excepto por bajo peso, que consulta por fiebre de cuatro días de evolución, vómito y orina fétida. Los paraclínicos evidencian una respuesta sistémica marcada, uroanálisis con nitritos positivos, leucocituria y bacteriuria, función renal normal, hemograma con 17660 leucocitos, proteína $C$ reactiva $(\mathrm{PCR})$ en $151 \mathrm{mg} / \mathrm{l}$. Se inicia manejo con amikacina. En el urocultivo crece Escherichia coli $>100000 \mathrm{UFC} / \mathrm{ml}$, sensible a la amikacina. Ecografía renal normal. Persiste la fiebre tras cinco días de manejo, con urocultivo de control negativo, por lo que se escalona a ceftriaxona. Ecografía renal de control muestra colección intrarrenal que se confirma con UROTAC, que evidencia la formación de abscesos en ambos riñones, de predominio derecho (figuras 1 y 2). No tiene historia de estreñimiento ni presenta alteraciones a nivel de la columna vertebral. Estudios adicionales incluyen $\mathrm{VIH}$ negativo e inmunoglobulinas normales. Se maneja con amikacina y ceftriaxona completando 9 y 24 dias respectivamente, con control del proceso infeccioso. Tomografía de control evidencia formación de cicatrices parenquimatosas. Uretrocistografía retrograda miccional no evidencia reflujo vesicoureteral, solo residuo postmiccional (figura 3).

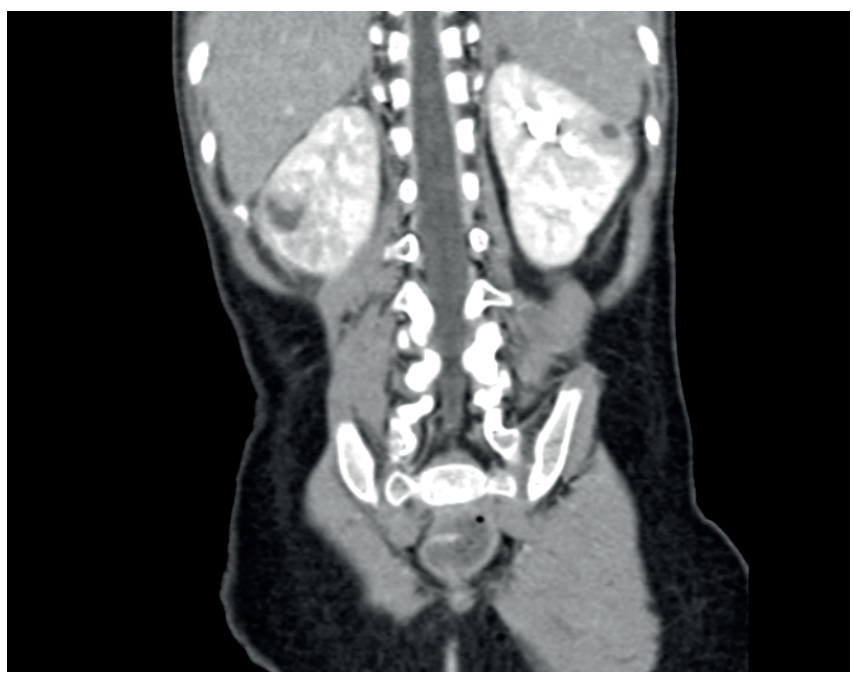

Figura 1. UROTAC que evidencia la formación de abscesos en ambos riñones, de predominio derecho.

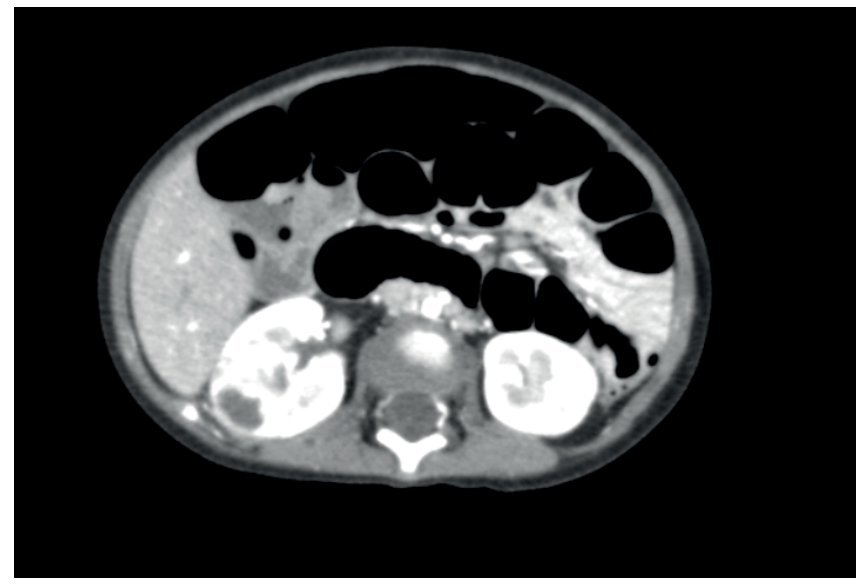

Figura 2. UROTAC que evidencia la formación de abscesos en ambos riñones, de predominio derecho.

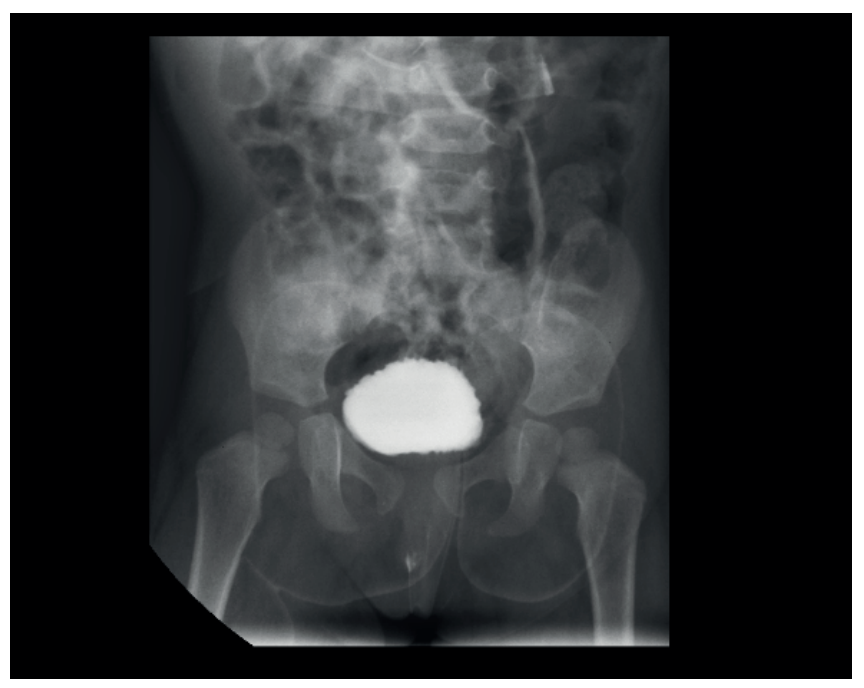

Figura 3. U retrocistografía retrograda miccional no evidencia reflujo vesicoureteral, solo residuo posmiccional.

\section{Paciente 2}

Paciente femenina de 8 meses, sin antecedentes de importancia, consulta por dos días de fiebre y vómito. Uroanálisis con leucocituria, hemograma con 17540 leucocitos, PCR en 392,2 mg/l. Se inicia manejo con amikacina. Urocultivo reporta E. coli $>100000$ UFC/ $\mathrm{ml}$, sensible al antibiótico. Ecografía renal inicial reporta nefromegalia derecha (riñón derecho mide 79 x $38 \times$ $34 \mathrm{~mm}$, parénquima de $12 \mathrm{~mm}$, riñón izquierdo mide 68 x 29 x $33 \mathrm{~mm}$, parénquima de $11 \mathrm{~mm}$ ). Persiste la fiebre, con urocultivo de control negativo. Se cambia manejo antibiótico a ceftriaxona. En la ecografía renal de control 


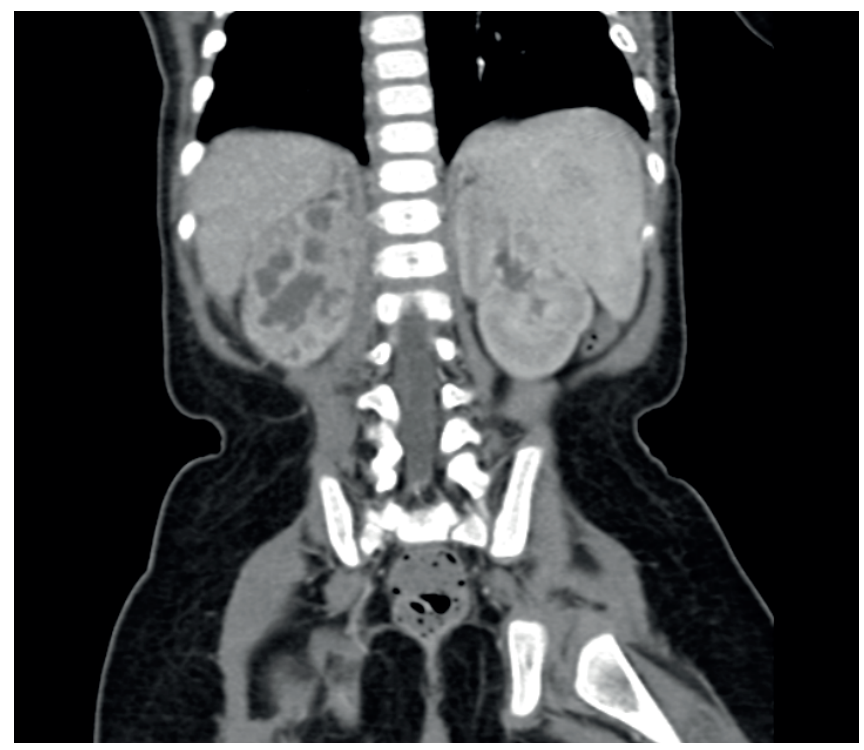

Figura 4. TAC de abdomen contrastado que evidencia masas renales en un espectro entre pielonefritis y abscesos renales.

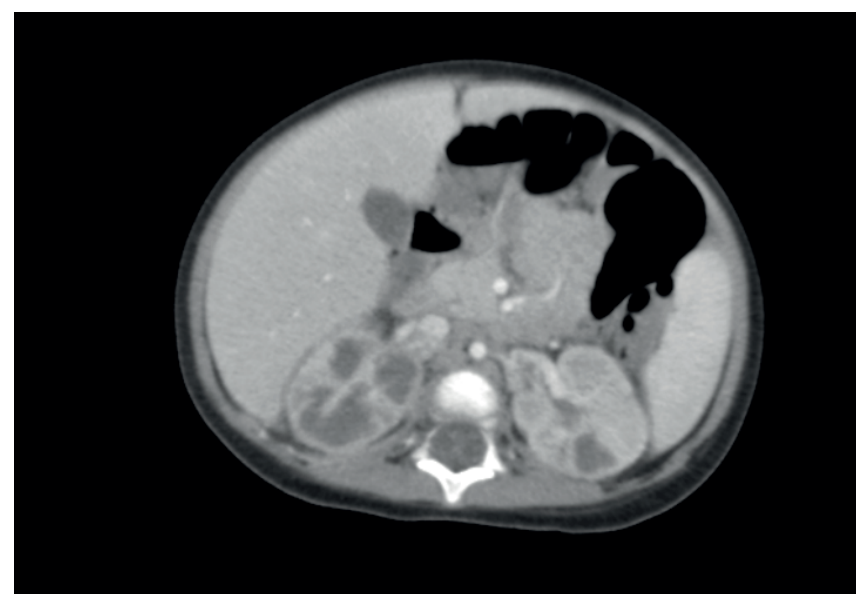

Figura 5. TAC de abdomen contrastado que evidencia masas renales en un espectro entre pielonefritis y abscesos renales.

persiste la nefromegalia derecha y un leve aumento del tamaño del riñón izquierdo. Se cambia manejo a meropenem. Tras cinco días de tratamiento y por persistencia de fiebre se realiza TAC de abdomen contrastado que evidencia masas renales en un espectro entre pielonefritis y abscesos renales, de predominio derecho (figuras $4 \mathrm{y}$ 5). Se administra antibiótico biconjugado con amikacina y meropenem, que lleva evolución clínica y paraclínica favorable. A los 21 días TAC de control evidencia disminución del tamaño de las lesiones en un $40 \%$, por lo que se completa 28 días con meropenem. Ecografía renal de control sin deterioro. Se deja orden de uretrocistografía miccional ambulatoria pero no es posible realizar seguimiento a la paciente. Ambas pacientes salen con profilaxis antibiótica.

\section{Discusión}

Se describen dos casos de pacientes con diagnóstico final de absceso renal, que se presentaron tras una primera infección urinaria con evolución tórpida, pese a recibir desde el inicio un antibiótico con sensibilidad in vitro $y$ con urocultivo de control negativo. La sospecha se da por la persistencia de la fiebre por más de 72 horas y la no disminución de los reactantes de fase aguda. Cabe anotar que en nuestro servicio se inicia el manejo empírico de la infección urinaria con un aminoglucósido o una cefalosporina de tercera generación, teniendo en cuenta las altas resistencias detectadas en nuestra institución a las cefalosporinas de primera generación, ampicilina, ampicilina sulbactam y trimetoprim sulfametoxazol (1). El inicio de uno u otro antibiótico se define con base en la función renal, la existencia de alteraciones renales previas, el estado séptico o el uso previo de antibióticos. Según el antibiograma se modifica el manejo antibiótico a uno de menor espectro y toxicidad. El interés de esta revisión radica en que en la institución, en la que venimos laborando desde hace más de 20 años, es la primera vez que se presentan dos casos consecutivos de formación de abscesos renales en el transcurso de una infección urinaria; sin embargo, para descartar un posible fallo terapéutico de la amikacina, se solicitó a vigilancia epidemiológica y farmacia que hicieran el seguimiento correspondiente, no habiéndose reportado otras fallas con el uso del antibiótico en el hospital, con lo que se verifica el cumplimiento de buenas prácticas para su embalaje y suministro en monodosis.

Es bien sabido que la severidad de la infección urinaria depende de varios factores, como son la presencia de malformaciones en el tracto urinario, la interacción entre el patógeno-huésped y la prontitud del tratamiento. Las formas más severas de presentación son la nefritis aguda focal bacteriana, el absceso renal y la pionefrosis, las cuales no son comunes y se pueden confundir con una pielonefritis (2). La nefritis focal aguda o nefronía se ha considerado como un estadio intermedio entre la pielonefritis y el absceso renal, y se puede presentar en $8-19 \%$ de las infecciones urinarias febriles en pediatría, caracterizándose por un curso más prolongado y exáme- 
nes de laboratorio más elevados (3), datos que coinciden con los dos expuestos. Los abscesos renales afectan con mayor frecuencia a las mujeres (4), se presentan en todas las edades, siendo el promedio de edad, en una serie reportada, de 13 años (5), mucho mayor que los casos de las dos niñas reportados.

La sintomatología del absceso renal es vaga, con o sin fiebre, dolor abdominal o lumbar, náuseas/vómito, apariencia enferma y a nivel de laboratorio el cuadro hemático muestra leucocitosis, hay elevación de los reactantes de fase aguda, que se puede confundir con facilidad con una pielonefritis, lo cual puede retardar el diagnóstico (5-7), datos que coinciden con los casos que reportamos. También puede presentarse como un síndrome febril de causa desconocida, asociado a malestar general, y es necesario un alto índice de sospecha (7). La media de duración de los síntomas previa al diagnóstico es de diez días (5). La mayoría son unilaterales, con predominio en el lado derecho (8), que coinciden con nuestros pacientes. Sus consecuencias pueden ser graves y pueden incluir sepsis, daños renales graves o incluso pérdida renal (9), por lo que es importante el diagnóstico oportuno para planificar un tratamiento más prolongado o la necesidad de intervención quirúrgica (2), ya que un diagnóstico tardío aumenta las complicaciones y la mortalidad (10). Pueden generarse por vía ascendente, hematógena o por contigüidad, y haber compromiso cortical (siendo generalmente únicos, origen hematógeno y por $\mathrm{S}$. aureus) o corticomedular (por infección u obstrucción urinaria) (11). Los secundarios a infección urinaria son los más frecuentes (en una serie el $81 \%$ ), seguidos de diseminación hematógena (en la misma serie del 6\%) o de causa desconocida (12\%) (5). En nuestras pacientes su origen fue la infección urinaria. Los originados por contigüidad son raros (8). Generalmente son producidos por microorganismos Gram negativos y en menor frecuencia por enterococo en el curso de una infección urinaria, especialmente si se asocia a factores predisponentes como urolitiasis, diabetes, inmunosupresión, obstrucción urinaria (10), vejiga neurogénica, tumor, enfermedad poliquística, diálisis peritoneal (12), duplicación pélvica ureteral (4) y, especialmente, reflujo vesicoureteral de cualquier grado, que se ha reportado en el $43 \%$ de los casos (6, 10). Otros factores asociados incluyen cirugía del tracto urinario, trasplante renal, cirugía intraabdominal, trauma renal, diabetes mellitus e inmunodeficiencias (12).

Nuestros aislamientos fueron de E. coli. En la literatura se ha reportado que los microorganismos Gram negativos, especialmente la E. coli, son los patógenos más comúnmente encontrados si hay una infección urinaria previa (7), aislándose algunas veces cepas productoras de BLEE (13). El S. aureus predomina cuando la diseminación es hematógena (14), aunque también puede ser ocasionada por streptococcus (infecciones de la piel y tejidos blandos, dentales, del tracto respiratorio, intraabdominales, cardiacas, genitales, relacionadas a catéteres intravasculares o uso de drogas ilícitas intravenosas) (12). Otros microorganismos involucrados son la Bartonella henselae, Mycobacterium tuberculosis y microorganismos anaerobios (estos en general asociados a bacterias Gram negativas, aunque pueden estar solos) (15). Aunque el urocultivo se negativice con el tratamiento antibiótico, en el absceso renal aún puede haber crecimiento bacteriano por el mismo microorganismo (13). No es frecuente que una pielonefritis dé origen a un absceso renal, pero una nefronía no tratada adecuadamente sí puede originarlo (15). El urocultivo puede ser negativo a pesar de presentar alteraciones en el uroanálisis (2), aunque también estos dos paraclínicos pueden ser normales si el absceso no tiene comunicación con el sistema colector o ha recibido previamente antibióticos (7). En el cultivo del absceso renal puede aislarse un microorganismo diferente al del urocultivo o ser polimicrobiano $(10,12)$. En pacientes inmunocomprometidos puede detectarse Candida y Aspergillus (11).

La ecografía renal de control no pudo detectar el absceso renal en el segundo caso, situación descrita por otros autores (7), la cual ha mostrado una baja sensibilidad (2), pero continúa siendo el examen más rentable para este fin (16). La presencia de nefromegalia debe hacer sospechar esta condición, completando el estudio con el TAC (7), similar a lo encontrado por nosotros. En la ecografía se observará un área hipoecoica rodeada de un área hipoecoica y un Doppler mostrará una región interna no vascularizada rodeada en su periferia por una zona vascularizada (8). Aunque algunos reportan que la ecografía puede detectar el $93 \%$ de los abscesos renales, otros indican que sus hallazgos pueden ser equívocos, por lo que se recomienda el TAC con contraste que define mejor la extensión de las lesiones $(9,10)$, como sucedió especialmente en el segundo caso que reportamos. La resonancia magnética se puede usar en casos de alergia a los medios de contraste o insuficiencia renal (11). La urografía por resonancia magnética puede valorar algunas anormalidades del tracto urinario, aportando información tanto estructural como funcional, por lo que se ha convertido en una herramienta de diagnóstico importante en los últimos tiempos (2). En ocasiones la ecografía renal o la TAC no pueden diferenciar entre nefronía y absceso, en 
esta situación la punción y aspiración con cultivo de la lesión pude ayudar (15). La gammagrafía renal DMSA cuantificará la función renal (15) al igual que la formación de cicatrices, que ha sido reportada en el $91 \%$ de los pacientes a los que se les realizó (6). La mejoría en las técnicas de imagen ha venido aumentando el diagnóstico de nefronias, indicando que posiblemente no son tan inusuales como se consideraba (2). En el seguimiento, la ecografía renal mostrará una progresiva resolución de las colecciones. Con el TAC se puede apreciar la resolución de los abscesos y la gammagrafía renal DMSA mostrará la extensión de la inflamación renal, la formación de cicatrices (en la mayoría de los pacientes), alteraciones en la función renal y se correlacionará con la mejoría $(7,9)$.

Dentro de los diagnósticos diferenciales están la nefronía lobar aguda, pielonefritis aguda complicada con necrosis papilar, pielonefritis enfisematosa, malacoplaquia, tuberculosis o carcinomas (8).

El manejo depende del estado del paciente, el tamaño y número de abscesos, si el absceso es unilocular o septado, uropatías asociadas y la función del riñón comprometido (15). El tratamiento incluye antibióticos intravenosos, drenaje percutáneo, drenaje quirúrgico o nefrectomía (9). Están asociados a una evolución tórpida la presencia de abscesos de gran tamaño, uropatía obstructiva, reflujo vesicoureteral grave, diabetes mellitus, microorganismos formadores de gas y edad avanzada (10). Si el urocultivo revela un microorganismo, se espera que este sea el causal del absceso, y el manejo antibiótico debe depender de la susceptibilidad del microorganismo. Pero si existen cálculos renales, se aconseja realizar punción del absceso para definir mejor el microorganismo, ya que puede ser polimicrobiana (15). La respuesta clínica, por lo general, se observará dentro de 48 a 72 horas después de iniciar el tratamiento (4). Se aconseja cirugía si no hay mejoría en los primeros tres días de manejo (10), en los casos de pacientes con abscesos entre 3 a $5 \mathrm{~cm}$ en quienes la punción percutánea fracasó o no mejoraron con el manejo médico, si el absceso es mayor de $5 \mathrm{~cm}$, hay inmunocompromiso o en paciente séptico (11). En general los abscesos menores de $3 \mathrm{~cm}$, los más frecuentes en pediatría, mejorarán con antibióticos (5). La duración óptima del manejo antibiótico no está establecida, pero tres semanas fueron mejores que dos semanas (15). Algunos consideran dos semanas de antibióticos intravenosos seguidos de dos a cuatro semanas de antibióticos orales (12). En una revisión reciente el $75 \%$ recibió manejo antibiótico combinado y el $25 \%$ monoterapia (10). En otra revisión, la duración del manejo antibiótico fue de 14 a 60 días y se cambió el tratamiento intravenoso por el oral guiado por la resolución de la fiebre, la disminución de la respuesta inflamatoria y el resultado de la ecografía de control (2). La duración de los antibióticos también puede ser guiada por imágenes hasta la resolución de las lesiones (5). En promedio la resolución de las lesiones en un estudio fue de 19,5 días, algo mayor (23 días) sin drenaje que con drenaje (18,5 días), aunque sin significancia estadística (5). En nuestros pacientes el manejo fue solamente médico, ya que cirugía pediátrica no consideró necesaria ninguna intervención quirúrgica. Todo el tratamiento fue intravenoso, guiado por el resultado de los antibiogramas. La asociación de los antibióticos se debió a que con la monoterapia no se logró controlar la respuesta inflamatoria sistémica.

La pérdida renal oscila entre un 5 y un $20 \%$ (4), y para evitar esta situación debe haber diagnóstico y tratamiento tempranos.

\section{Conclusiones}

El absceso renal en pediatría no es común en nuestra institución, lo que concuerda con lo reportado en la literatura. La persistencia de la fiebre más allá de tres días en un niño con infección urinaria debe hacer sospechar la formación de una colección supurada, especialmente si la ecografía inicial o de control evidencian nefromegalia, hay en el cuadro hemático leucocitosis y los reactantes de fase aguda persisten elevados. Cuando existen dudas los estudios de imágenes se deben ampliar con TAC renal con contraste o RNM con contraste, ya que en ocasiones la ecografía renal no detectará las lesiones. Es importante el diagnóstico precoz para definir mejor el manejo antibiótico, su duración, valorar factores predisponentes y un posible manejo quirúrgico. En los dos casos reportados llama la atención que, a pesar de un adecuado manejo antibiótico, no fue posible evitar la evolución a la formación de abscesos renales múltiples.

\section{Responsabilidades éticas}

Protección de personas y animales: los autores declaran que para esta investigación no se han realizado experimentos en seres humanos ni en animales.

Confidencialidad de los datos: los autores declaran que han seguido los protocolos de su centro de trabajo sobre la publicación de datos de pacientes. 
Derecho a la privacidad y consentimiento informado: los autores declaran que en este artículo no aparecen datos de pacientes.

Conflicto de intereses: los autores declaran no tener conflicto de intereses.

\section{Referencias}

1. López J. Infección urinaria en pediatría. Evaluación del antibiótico empírico inicial. Pediatría. 2008; 42(2): 51-62.

2. Bitsori M, Raissaki M, Maraki S \& Galanakis E. Acute focal bacterial nephritis, pyonephrosis and renal abscess in children. Pediatr Nephrol. 2015; 30: 1987-93.

3. Piñera C, Loyola F \& Hernández P. Nefronia en pediatría: dentro del espectro de las infecciones urinarias. Serie clínica y revisión de la literatura. Rev Chilena Infectol. 2015; 32(5): 564-8.

4. Seguias L, Srinivasan K \& Mehta A. Pediatric Renal Abscess: A 10-year Single-Center Retrospective Analysis. Hospital Pediatrics. 2012; 2(3): 161-6.

5. Linder BJ \& Granberg CF. Pediatric renal abscesses: a contemporary series. Jornal of Pediatric Urology. 2016; 12(2): 99 e1-5.

6. Cheng CH1, Tsai MH, Su LH, Wang CR, Lo WC, Tsau YK, Lin GJ, Huang YC, Chiu CH \& Lin TY. Renal abscess in children: a 10-year clinical and radiologic experience in a tertiary medical center. Pediatr Infect Dis J. 2008; 27(11): 1025-7.

7. Cancelinha C, Santos L, Ferreira C \& Gomes C. Renal abscesses in childhood: report of two uncommon cases. BMJ Case Rep. 2014. doi: 10.1136/bcr-2013-202408.
8. Comploj E, Cassar W, Farina A, Gasparella P, Trenti E et al. Conservative management of pediatric renal abscess. Journal of Pediatric urology. 2013; 9: 1214-7.

9. Consuelo M, Dominguez C, Estornell F \& García-Ibarra F. Tratamiento conservador de un absceso renal múltiple. Cir Pediatr. 2013; 26: 150-2.

10. Fullá J, Storme O, Fica A, Varas A, Flores J, Marchan F \& Varas D. Abscesos renales y peri-renales: análisis de 44 casos. Rev Chil Infect 2009; 26 (5): 445-51.

11. Ybarra ME, Ambrosio LD \& Fioravanti A. Descripción del caso presentado en el número anterior: absceso renal. Arch Argent Pediatr 2011; 109(2): 173-9.

12. Lohr JA \& O'Hara SM. Renal (Intrarenal and Perinephric) abscess. Chapter 52. Long: Principles and Practice of Pediatric Infectious Diseases, 3rd ed. 2008).

13. Hochreiter D, Lin J, Singh J \& Shetty AK. Renal abscess due to community-adquired extended-spectrum B-lactamase-producing Escherichia coli in a 15-year-old girl. Urology. 2015; 85: 1480-2.

14. Yock LC \& Boyce TG. Fever and Abdominal Pain Following Incision and Drainage of a Cutaneous Abscess. Clinical Pediatrics. 2015; 54(3): 296-8.

15. Gonzales ET \& Kaplan SL. Renal abscess. Feigin and Cherry's Texbook of Pediatrc Infectious Diseases. James D. Cherry, Gail J Harrison, Sheldon L. Kaplan, William J Steinbach \& Peter J Hotez ed. Elsevier. United States of America. $7^{\text {a }}$ edición. 2014. pp. 553-8.

16. Swischuk LE. Radiología en el niño y en el recién nacido. Editorial Marbán libros SL. Edición en español. Madrid, España. 2005. pp. 606 